\title{
Expression of Sport Experiences between Cadet and Junior Basketball Players
}

\author{
Romualdas Malinauskas, Šarūnas Zablockis, Šarūnas Ajauskas \\ Lithuanian Sports University, Kaunas, Lithuania
}

\begin{abstract}
Background. The hypothesis of this study is formulated as follows: the experience of junior basketball players in competitions will be more valuable than that of cadet basketball players. The aim of our study was to examine the peculiarities of youth and basketball players' sport experiences.

Methods. A total of 104 basketball players, 47 cadets and 57 juniors participated in the study. Survey questionnaire is used for the study. The following methodologies were used: Athlete's Personal Experience Survey (Athletic Coping Skills Inventory, ACSI-28) and the Sport Experiences Questionnaire (SEQ).

Results. The results of the study revealed statistically significant differences $(p<.05)$ in personal sport experiences (athletic endurance skills) among basketball players of different age groups according to the following indicators: the coach's influence on basketball players, concentration, athletes' self-confidence and resilience. The results of the study of athletes' competitive experiences revealed that there were statistically significant differences $(p<.05)$ between cadet and junior basketball players in competition experience. No statistically significant differences were found in terms of risk and progress parameters.

Conclusions. The coach's influence was greater for the cadet basketball players. Concentration, self-confidence and resilience were better among junior basketball players. This shows that when competing, junior basketball players have higher levels of concentration compared to the cadet group, as they are more confident and can better cope with tension. In addition, it was found that the experience of junior basketball players in competitions is richer than that of cadet basketball players.
\end{abstract}

Keywords: sport experience, junior, cadet, basketball players, basketball.

\section{INTRODUCTION}

"Experience is a system of personally significant meanings that captures knowledge, abilities, skills and values" (Jackūnas, 2008, p. 22). The knowledge of recurring phenomena, its frequency, characteristics, connection and regularities are well reflected in an athlete's sport experience (Jackūnas, 2008).

Engagement in sports activities in childhood and adolescence is associated with positive physical, cognitive, and psychosocial development as well as early experiences in sport activities (Brown,
Female, \& Darmawan, 2017; De Greef, Bosker, Oosterlaan, Visscher \& Hartman, 2018).

Data from many studies in the European Union showed the importance of participation in physical activity and that the overall rate of physical activity in people is still insufficient: only $4.5-37.6 \%$ of boys and girls meet current guideline norms (Kalman et al., 2015). In recent decades, there has been a steady global decline in adolescent participation in sports (Adams, 2006; Knuth \& Hallal, 2009; Suris, Michaud, Chossis \& Jeannin,

Copyright (C) 2021 Romualdas Malinauskas, Šarūnas Zablockis, Šarūnas Ajauskas. Published by Lithuanian Sports University. 
2006). This situation is worrisome. Over the past three decades, many scholars have stressed the impact which enjoyment has over understanding people's dedication to participate in sports and how it helps with developing sport initiatives. According to Self-Determination Theory (Deci \& Ryan, 2000), participation in sport is driven by personal interest, and enjoyment is the most beneficial factor for participants' well-being and long-term motivation in sports and physical activity (Hagger \& Chatzisarantis, 2008; Owen, Smith, Lubans, Ng \& Lonsdale, 2014; Ryan \& Deci, 2007; Texeira, Carraca, Markland, Moussa et al., 2012). Conversely, more people stated that the engagement in sports for external rewards brought on more negative outcomes. Public health researchers have recently argued that health promotion initiatives could be effective in improving and developing empirical and theoretical knowledge on enjoyable experiences in the context of physical activity (Jallinoja, Pajari \& Absetz, 2010; Phoenix \& Orr, 2014; Ekkekakis, 2017).

In order to understand the motivation behind participation in sport, it is necessary to find out the resulting experiences and answer the question of why people take part in the first place. However, for a long time, the questionnaires assessing the most valued sport experience were non-existent (Luiggi, Maïano \& Griffet, 2019). In research of incentives in sport there is a number of surveys that question the motivation for sport such as the Participation Motivation Questionnaire (Gill, Gross \& Huddleston, 1983), The Behavioral Regulation Questionnaire (Lonsdale, Hodge \& Rose, 2008), Validation of the Revised Sport Motivation Scale (Pelletier, Rocchi, Vallerand, Deci \& Ryan, 2013) and the Physical Activity and Leisure Motivation Scale (Molanorouzi, Khoo \& Morris, 2015). However, factual knowledge of what is an enjoyable experience in sport has been largely observed in qualitative and experimental studies. In qualitative research, some of the previous findings have shown that the competitive environment, stress, and competition pressure are keys to understanding participation in sport (Belanger, 2011; Craike, Symons \& Zimmerman, 2009; Uijtdewilligen et al., 2011). However, these results were contradicted by other studies revealing that sporting experience was sometimes an important reason for nonparticipation (refusal to exercise) (Allender, Cowburn \& Foster, 2006; Brooks \& Magnusson, 2007; Coleman, Cox \& Roker, 2007; Craike \& others, 2009; Cote \& Vierimaa, 2014; Knowles, Niven \& Fawkner, 2011; Yungblut, Schinke \& McGannon, 2012).

There were also discoveries that have demonstrated the importance of the social surroundings of the participants. For instance, finding oneself in a hostile environment during play has been cited as a reason for dissatisfaction and withdrawal from sports (Yungblut et al., 2012; Belanger et al., 2011). While executing the experimental studies, special attention was paid to sports programs where the importance of intensity determines future participation in sports activities. Previous findings have shown that people did not experience any pleasure beyond the intensity threshold and thus did not have a repeat sport experience (Ekkekakis, Parfitt \& Petruzello, 2011). In sports, great attention is paid to confrontation with risks and dangers (injuries, painful defeats). Following this logic, risk culture in sport has been extensively studied and many authors have stated that sport culture increases risk-taking behavior and presents it as normality which contributes to progress and victory (Nixon, 1992; Saragiotto et al., 2014; Schnell, Mayer, Diehl, Zipfel \& Thiel, 2014). Nixon (1992) has shown that athletes' rivalry, risk-taking, suffering, pain, and trauma are part of the sport, because exercise can cause suffering and it should be considered normal. As Howe (2004) noted, "the initial worries about risk in sport begin when people are forced to risk it all and win at any cost". Lately the possibility of injury has become the main risk (Saragiotto et al., 2014; Schnell et al., 2014). Recent research has shown that past experiences are related to the likelihood and frequency of behavior recurrence (Kiviniemi, Voss-Humke \& Seifert, 2007; Van Cappellen, Rice, Catalino \& Fredrickson, 2017 Wang, 2011; Wirtz, Kruger, Scollon \& Diener, 2003). Hence, it was believed that a questionnaire of recalled past experiences could help determine the experiences teens would look for in their chosen sport. Previous questionnaires were derived from motivation theories and focused on why people participate in sport (Gill et al., 1983; Lonsdale et al., 2008; Pelletier et al., 2013; Molanorouzi et al., 2015). Thus, the participants were asked to share their reasons for participation. The Sport Experiences Questionnaire (SEQ, Luiggi et al., 2019) asked participants to respond to their enjoyment and experience in specific situations. The responses are expected to help understand reasons behind people's 
participation. Previous findings have demonstrated how the experienced pleasure directly affects the ability to understand the people's future behaviors. Thus, adolescents who have strongly agreed to value past risk experiences (for example) are likely to seek such experiences in the future through participation in sports (Luiggi et al., 2019).

The results of SEQ prove that the experience, progress, and risk of competition are perceived differently by adolescent athletes (Luiggi et al., 2019). This implies that the knowledge of different personal experiences could be utilized by sports organisers and coaches to stimulate the enjoyment factor of participating in sport. Moreover, when analyzing said experience, it is necessary to keep the coach's characteristics in mind. For example, in previous studies that analyzed the experiences of elite athletes (Becker, 2009), the participants of the study described their coach as one having positive qualities. One special feature that all players discussed was their coach's sense of humor: "He's just a funny person. He could make one laugh for days". Additionally, the players also described their coach as knowledgeable, passionate and energetic: "He knows what he's talking about", "He eats, sleeps and lives basketball" (Becker, 2012, p. 49).

The players' understanding of the coach's philosophy, system and style of play also were influenced by his beliefs about basketball and the way he was coached. The players described how "He came up with a set system and he didn't think about it twice", "He said, 'I've been doing this my whole career and I'll continue it'. It was a success, and that was really impressive," (Becker, 2012, p. 50). It appeared that the coach was very successful in changing players' perception towards the game. These findings highlight the importance of a strong philosophy of the coach, and a desire to remain true to that philosophy. Until now most research on coaching effectiveness has focused on the study of coaching behavior, despite the important role of coaching philosophy in players' athletic experiences (Becker \& Wrisberg, 2008; Potrac et al., 2006; Smith \& Cushion, 2006).

It should be noted that the analysis of experiences revealed a dimension in coaching style when players described the coach as "more of a players' coach". This terminology is more commonly used within the sports community, "players' coach" represents player-centered leadership that has not been systematically studied in the leadership literature because research has primarily focused on democratic and autocratic styles (Gilbert \& Trudel, 2004). Under this line of research, coaches who adopt a democratic style allow their athletes to set team goals, work at their own pace, express their opinions, and share the decision making (Chelladurai \& Saleh, 1980). "Players' coach" represents a style that can involve both autocratic and democratic behaviors. This style is characterized by the fact that it is player-oriented, meaning that the coach's behavior depends on what is best for the players or the team, at a given moment. The key feature of this coaching style are the players (Becker, 2012).

Many recent studies have looked into ensuring fair behavior in teams, and research shows that many coaches allow more time to play for the players they consider to be more talented (Solomon, Striegel, Eliot, Heon, Maas, \& Wayda, 1996; Solomon et al., 1996). This can often result in negative experiences for the players. Negative experiences related to coaches often result in players trying to avoid player-coach contact: "I hated having to analyze the games, I just did not want to be near [the coach]. I haven't even gone to take additional shots". While some coaches may not be fully aware of the negative experience (De Marco, Mancini \& West, 1997; Krane, Eklund, \& McDermott, 1991), others may ignore it. It is pointed out that both positive and negative coach behaviors can affect players' personal and competitive experiences (e.g., Kenow \& Williams, 1999).

In conclusion, the topic of the peculiarities of sports experiences of cadet and junior basketball players is relevant because the parameters of both personal sports and competitive experiences, such as concentration, failure, and resilience, are among the key factors determining the success of sporting activities. In addition, studies do support the importance of said factors (Fraser-Thomas \& Côté, 2009; Gencer \& Öztürk, 2018). According to research data (Fraser-Thomas \& Côté, 2009), all the best athletes state that overcoming failures, resistance to pressure, and resilience are the key to success, so the relevance of the study of the peculiarities of sports experiences of both cadet and junior basketball players is undeniable. There is a lack of research in the literature on the sporting experiences of adolescent basketball players. There is a problem yet to be solved: what is the difference between cadet and junior players' sports experiences? The formulation of the problem allowed to generate the hypothesis of this 
research: the experience of junior basketball players in competitions will be richer than that of cadet basketball players. The hypothesis is formulated on the basis of Malinauskas and Zablockis (2020) research data. The aim of the study is to determine the peculiarities of cadet and junior players' sports experiences. Research tasks:

1. To study and compare the personal sports experiences (athletic endurance skills) of cadet and junior basketball players.

2. To determine the experience of cadet and junior basketball players in competitions.

\section{METHODS}

Research participants. A targeted selection procedure was used. A total of 104 basketball players participated in this research, 47 cadets and 57 junior players from Kaunas, Tauragè, Raseiniai, Šiauliai and Šilute. Participants were asked to fill in the questionnaire prior to training. The questionnaire was anonymous and confidential; only generic information was used. This research was permitted by the Social Research Ethical Committee of the University, 20200210 No. SMTEK-9.

Measures. Research was completed using a questionnaire. Two methods were used. First method - Description of Sportsmens' personal experience (Athletic Coping Skills Inventory, ACSI28; Smith, 1995). The questionnaire consisted of 28 statements, which were to be given a score from $1-$ never; 2 - seldom; 3 - often and 4 - almost always. Questionnaire ACSI-28 researched target setting, coach's influence, concentration, overcoming of failures, self-esteem, and performance under pressure: all these aspects are reflected in sport experience.

Second method - Sport Experiences Questionnaire (SEQ)) (Luiggi et al., 2019). The questionnaire included 14 statements, i.e., "Do I do things I have never done", "Do I risk even if I can lose it all", "Am I amongst the best" etc. Participants had to mark their answers from 1 (totally disagree) to 7 (absolutely agree).

Statistical analysis. PSS for Windows version 21.0 software was used to calculate the results of this survey. Average (M) and standard deviation (SD) of indicators were calculated. To determine the reliability of the mean difference between the age groups, the student's $t$ criterion was applied to independent samples.

\section{RESULTS}

Based on ACSI-28 methodology, basketball players' personal sport experience can be subdivided into 7 categories: overcoming failure, coach's influence, concentration, self-esteem, target setting, pressure resilience and resistance to anxiety. Analysis of received results is listed below. According to the following parameters: overcoming failures, goal setting, resistance to anxiety, no statistically significant differences were found (Table 1).

When analyzing concentration, self-confidence, and resilience to pressure, junior basketball players performed better than cadet basketball players. Research showed that the role of the coach, according to the averages, is significantly more important for cadets $2.33 \pm 0.55$ points, than for junior age group participants $2.01 \pm 0.56$ points. A statistically significant difference $t(102)=2.89$ was observed between the two age groups; $p<0.01$ ( $\mathrm{p}=$ 0.005 ). Thus, it can be said that the coach's influence on cadet basketball players is greater than on junior players. When analyzing the concentration results, it was revealed that the average concentration of cadet players was $1.80 \pm 0.48$ points, while juniors had it higher and it amounted to $2.01 \pm 0.54$ points. Statistically significant differences were found
Table 1. The statistical indicators of athletes' personal experiences among cadet and junior basketball players $(M \pm S D)$ *

*Note $(M \pm S D)$ - mean and standard deviation.

\begin{tabular}{|l|l|l|c|c|}
\hline \multicolumn{1}{|c|}{ Variable } & \multicolumn{1}{|c|}{$\begin{array}{c}\text { Cadets, } \\
\mathbf{n}_{\mathbf{1}}=\mathbf{4 7}\end{array}$} & \multicolumn{1}{c|}{$\begin{array}{c}\text { Juniors, } \\
\mathbf{n}_{2}=\mathbf{5 7}\end{array}$} & $\begin{array}{c}\text { Scores of } t \text {-test, } \\
\mathbf{d f}=\mathbf{1 0 2}\end{array}$ & \multicolumn{1}{c|}{$p$} \\
\hline Adversity & $1,66 \pm 0,48$ & $1,70 \pm 0,48$ & -0.34 & $p>0,05$ \\
\hline Coachability & $2,33 \pm 0,55$ & $2,01 \pm 0,56$ & 2.89 & $p<0.01$ \\
\hline Concentration & $1.80 \pm 0,48$ & $2,01 \pm 0,54$ & -2.03 & $p<0.05$ \\
\hline Confidence & $2,10 \pm 0,51$ & $2,31 \pm 0.38$ & -2.45 & $p>0,05$ \\
\hline Goal setting & $1,49 \pm 0,51$ & $1,41 \pm 0,57$ & 0.77 & $p>0,05$ \\
\hline Peaking & $1,57 \pm 0,61$ & $1,81 \pm 0,49$ & -2.20 & $p<0.05$ \\
\hline Wony & $1,72 \pm 0,64$ & $1,72 \pm 0,61$ & -0.05 & $p>0.05$ \\
\hline
\end{tabular}


according to the student's $t$-test, because $t(102)=$ $-2.03 ; p<0.05(\mathrm{p}=0.045)$, so it can be stated that the concentration levels of junior basketball players during the competition are higher than that of cadet basketball players, and they are able to concentrate better. After analyzing the results of self-confidence, it became clear that the average self-confidence of young basketball players was $2.10 \pm 0.51$ points, and that of young basketball players $2.31 \pm 0.38$ points. Using student's $t$ criteria for independent samples, statistically significant differences were found between groups $t(102)=-2.45 ; p<0.05(\mathrm{p}=0.016)$. The data of the pressure resilience study showed that the resilience to pressure of cadet basketball players corresponded to $1.57 \pm 0.61$ points, junior basketball players to $1.81 \pm 0.49$ points. Using student's $t$-test, statistically significant differences between groups were revealed $t(102)=-2.20$; $p<0.05(\mathrm{p}=0.030)$. Thus, it can be concluded that junior basketball players cope much better with the tension of the competition than cadet basketball players.

The results of the Sport Experiences Questionnaire (SEQ), according to the research methodology, are presented by showcasing the results of three subscales: risk indicators, competing indicators, and progress indicators. The risk analysis showed that the average risk for cadet players was $4.93 \pm 1.04$ points, and for junior basketball players $5.03 \pm 1.01$ points. There were no statistically significant differences between age groups because $t(102)=0.47 ; p>0.05$ (Figure 1)

It was revealed that the experience of junior basketball players (competition experience) is greater than that of cadet basketball players, because the average score of junior basketball players is $5.13 \pm 0.85$ points, and that of cadet basketball players $4.71 \pm 0.74$ points, and this difference is statistically significant because, using student's $t$-test, $t(102)=-2.67 ; p<0.01$. (Figure 2).
Figure 1. Mean scores in risk taking
Figure 2. Mean scores in competition experience
* Note. Statistically significant difference between competition experience among cadet and junior basketball players $p<0,01$.
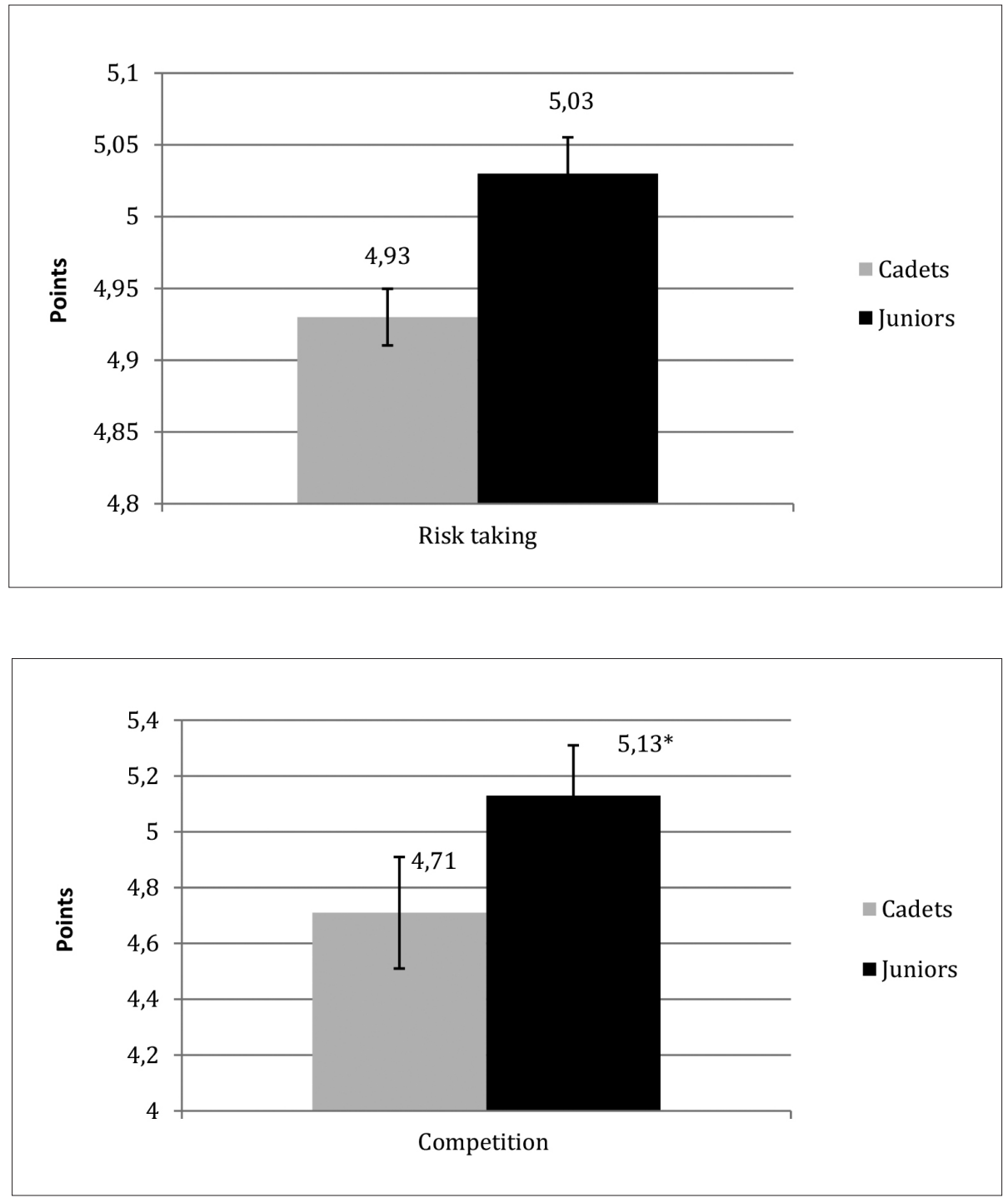
Figure 3. Mean scores in progress experience

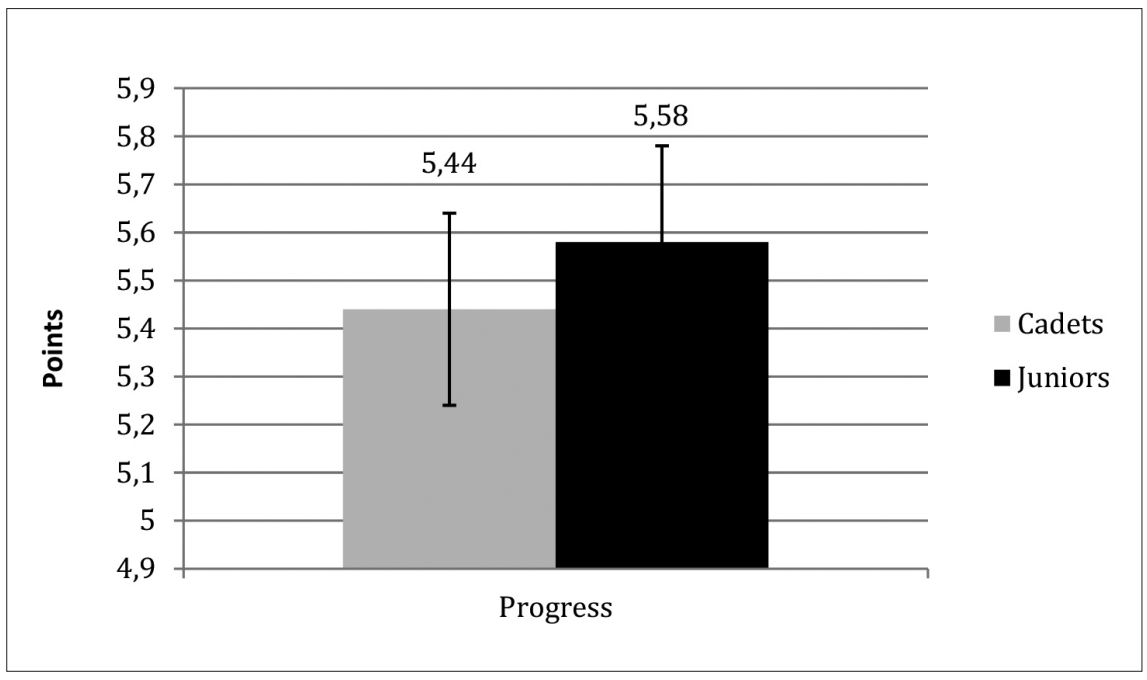

Analysis found that the average progress of cadet basketball players was $5.44 \pm 0.78$ points, and that of junior basketball players $5.58 \pm 0.74$ points. No statistically significant differences were found between the two groups, $t(102)=-0.95 ; p>0.05$ (Figure 3).

\section{DISCUSSION}

The main aim of this research was to identify cadet and junior basketballers' sport experience peculiarities with the hypothesis that junior players' sport experience will be more valuable compared to cadet players. This hypothesis was based on Malinauskas and Zablockis (2020) research results. This hypothesis is proven to be correct.

After having analysed questionnaire results, it has been noticed that coaches have a much bigger influence on cadets than on juniors. Becker (2012) states that the role of coach is one of the most important factors in the success of an athlete. The coach is usually the person responsible for the team's optimism or pessimism. Coaches who positively engage their team are usually the ones who win. Researched basketballers showed significant differences in concentration, self-esteem and pressure resilience. Junior basketball players showed better concentration, self-esteem and pressure resilience compared to cadet players. The conclusion can be drawn that junior basketball players are way more self-confident, more focused during the game and are more resilient towards pressure.

The analysis of competitive experience according to risk, competition and progress factors revealed statistically significant differences between the groups: junior basketball players' competition experience is greater than cadet basketball players, because this indicator is higher for junior basketball players. Based on experience with risk and progress, no statistically significant differences were found. According to Luiggi et al. (2019), adolescent athletes perceive competition experience, progress, and risk differently. This means that each of these experiences could be used by sports organizers or coaches to increase the enjoyment of participation in the sport.

Sport covers aspects like sharing, pressure, stress, feelings of unfairness, due to which people have different views to these experiences (Stalsberg \& Pedersen, 2010; Luiggi, Travert \& Griffet, 2018). The outcome from researchers Belanger et al. (2011), showed that competitive environment, stress and pressure to compete are some of the experiences to take into consideration in order to understand why youth want to participate in sports and compete. Other research identified these factors to be the one of the key factors causing people not to participate in sports (Yungblut et al., 2012). Researchers Hagger and Chatzisarantis (2008), Owen and others (2014) discovered people get involved in sports due to their curiosity, meanwhile pleasant experiences become the long term motivation to do sports.

To sum up, one could say that all sportsmens' experiences in any sport are an essential part of their journey to success. (Nixon, 1992, 1993, 1996; Saragiotto et al., 2014) also emphasizing the importance of experience in sport from the start to the end of a career in sports. Good, positive experiences can become the main drive to reach the top, meanwhile bad experiences can destroy sportsmen both physically and mentally and at times can be the reason to quit. Schnell, Mayer, Diehl, 
Zipfel \& Thiel, (2014) state that competitiveness, risk taking, physical pain and injuries are part of sport. In order for sportsmen to have good experiences that would serve them well, the role of coach is very important according to Horn (2008) and Becker (2012). According to Clifford \& Randolph (2020), coaches who positively engage with their team are more effective and victorious as they understand the importance of athlete excellence.

\section{CONCLUSIONS AND PERSPECTIVES}

Results of the study of personal sports experiences (athletic endurance skills) revealed statistically significant differences between basketball players of different age groups according to the following indicators: coach's influence on basketball players, concentration, athletes' selfconfidence and resilience to pressure parameters. For cadet players the coach's influence was greater. Concentration, self-confidence and pressure resilience were better among junior basketball players. This demonstrates that during the competition junior basketball players have higher levels of concentration compared to the cadet group, as they are more confident and can better cope with tension. In addition, it was found that the experience of junior basketball players in competitions (competition experience) is greater than that of cadet basketball players. No statistically significant differences were found between risk and progress parameters.

When discussing the prospects for further research, it may be interesting finding out what is the most enjoyable experience for teens in each sport. From a psychological standpoint, it would also be interesting to know whether the reported pleasure depends on social status or gender (these would be counted as factors related to participation in sport). For example, it is well known that girls with low social status are the least likely to play sports (Stalsberg \& Pedersen, 2010; Luiggi et al., 2018). Better knowledge of the experiences that adolescents want could help create appropriate programs that meet their expectations and encourage participation in sports activities.

\section{REFERENCES}

Adams, J. (2006). Trends in physical activity and inactivity amongst US 14-18 year olds by gender, school grade and race, 1993-2003: Evidence from the Youth Risk Behavior Survey. BMC PublicHealth, 6(57), 57. https://doi.org/10.1186/1471-2458-6-57

Allender, S., Cowburn, G., \& Foster, C. (2006). Understanding Participation in Sport and Physical Activity Among Children and Adults: a Review of Qualitative Studies. Health Education Research, 21(6), 826-835. https://doi.org/10.1093/her/cyl063

Becker, A.J. (2009). It's Not What They Do, It's How They Do It: Athletes Experiences Of Great Coaching. International Journal of Sports Science Coaching, 4, 93-119.

Becker, A. J. (2012). Collegiate Basketball Players' Experiences of Being Coached During a Turnaround Season. The Sport Psychologist, 26(1), 43-61.

Becker, A.J., \& Wrisberg, C.A. (2008). Effective Coaching in Action: Observations of Legendary Collegiate Basketball Coach Pat Summitt. The Sport Psychologist, 22, 197-211

Belanger, M., Casey, M., Cormier, M., Laflamme Fillion, A., Martin, G., Aubut, S., ... Beauchamp, J. (2011). Maintenance and decline of physical activity during adolescence: insights from a qualitative study. International Journal of Behavioral Nutritionand
Physical Activity, 8(1), 117. https://doi.org/10.1186/14795868-8-117

Brooks, F., \& Magnusson, J. (2007). Physical Activity as Leisure: The Meaning of Physical Activity for the Health and Wellbeing of Adolescent Women. Health Care for Women International, 28(1), 69-87. https://doi. org/10.1080/07399330601003499

Brown, K. A., Patel, D. R., \& Darmawan, D. (2017). Participation in Sports in Relation to Adolescent Growth and Development. Translational Pediatrics, 6(3), 150159. https://doi.org/10.21037/tp.2017.04.03

Chelladurai, P., \& Saleh, S.D. (1980). Dimensions of Leader Behavior in Sports: Development of a Leadership Scale. Journal of Sport Psychology, 2, 34-45

Coleman, L., Cox, L., \& Roker, D. (2007). Girls and Young Women's Participation in Physical Activity: Psychological and Social Influences. Health Education Research, 23(4), 633-647. https://doi.org/10.1093/her/ cym040

Cote, J., \& Vierimaa, M. (2014). The Developmental Model of Sport Participation: 15 Years After Its First Conceptualization. Science and Sports, 29, S63-S69

Craike, M. J., Symons, C., \&Zimmerman, J. A. M. (2009). Why Do Young Women Drop Out of Sport and Physical Activity? A Socioecological Approach. Annals of Leisure Research, 12(2), 148-172. https://doi.org/10. $\underline{1080 / 11745398.2009 .9686816}$ 
De Marco, G.M.P., Mancini, V.H., \& West, D.A. (1997). Reflections on Change: A Qualitative and Quantitative Analysis of a Baseball Coach's Behavior. Journal of Sport Behavior, 20, 135-163.

Deci, E.L., \& Ryan, R.M. (1985). Intrinsic Motivation and Self-determination in Human Behavior. New York: Plenum Press

De Greeff, J. W., Bosker, R. J., Oosterlaan, J., Visscher, C., \& Hartman, E. (2018). Effects of Physical Activity on Executive Functions, Attention and Academic Performance in Preadolescent Children: A Meta-analysis. Journal of science and medicine in sport, 21(5), 501-507.

Gilbert, W.D., \& Trudel, P. (2004). Analysis of Coaching Science Research Published from 1970-2001. Research Quarterly for Exercise and Sport, 75, 388-399.

Gill, D. L., Gross, J. B., \& Huddleston, S. (1983). Participation Motivation In Youth Sports. International Journal of Sport Psychology, 14, 1-14.

Ekkekakis, P. (2017). People Have Feelings! Exercise Psychology In Paradigmatic Transition. Current Opinion in Psychology, 16, 84-88. https://doi.org/10.1016/j. copsyc.2017.03.018

Ekkekakis, P., Parfitt, G., \& Petruzzello, J. (2011). The Pleasure and Displeasure People Feel When They Exercise at Different Intensities. Decennial Update and Progress Towards a Tripartite Rationale for Exercise Intensity Prescription. Sports Medicine, 41(8), 641-671. https://doi.org/10.2165/11590680-000000000-00000

Fraser-Thomas, J., \& Côté, J. (2009). Understanding Adolescents' Positive and Negative

Developmental Experiences in Sport. The Sport Psychologist, 23(1), 3-23.

Gencer, E., \& Öztürk, A. (2018). Goal Orientation and Motivational Climate in University Student-athletes. Asian Journal of Education and Training, 4(4), 290-294.

Hagger, M., \& Chatzisarantis, N. L. D. (2008). Self-determination Theory and the Psychology of Exercise. International Review of Sportand Exercise Psychology, 1(1), 79-103. https://doi.org/10.1080/ 17509840701827437

Horn, T.S. (2008). Coaching Effectiveness In The Sport Domain. In T.S. Horn (Ed.), Advances in Sport Psychology (3rd ed., pp. 239-267). Champaign, IL: Human Kinetics.

Howe, D. (2004). Sport, Professionalism and Pain: Ethnographies of Injury and Risk. New York, NY: Routledge.

Jackūnas, Ž. (2008). Patyrimas, patirtis ir supratimas. LOGOS-A Journal of Religion, Philosophy, Comparative Cultural Studies and Art, (56), 20-28.

Jallinoja, P., Pajari, P., \& Absetz, P. (2010). Negotiating Pleasures Health-seeking Lifestyles Participant of a Health PromotionIntervention. Health: AnInterdisciplinaryJournal for the Social Study of Health, Illness and Medicine, 14(2), 115-130. https://doi.org/10.1177/1363459309353292

Kalman, M., Inchley, J., Sigmundova, D., Iannotti, R. J., Tynjala, J. A., Hamrik, Z., Bucksch, J. (2015). Secular
Trends in Moderate-to-vigorous Physical Activity in 32 Countries from 2002 to 2010: A Cross-national Perspective. European Journal of Public Health, 25(Suppl 2), 37-40. https://doi.org/10.1093/eurpub/ ckv024

Kenow, L.J., \& Williams, J.M. (1999). Coach-athlete Compatibility and Athlete'sPerception of Coaching Behaviors. Journal of Sport Behavior, 22, 251-259.

Kiviniemi, M. T., Voss-Humke, A. M., \& Seifert, A. L. (2007). How Do I Feel About the Behavior? The Interplay of Affective Associations with Behaviors and Cognitive Beliefs as Influences on Physical Activity Behavior. Health Psychology, 26(2), 152-158. https:// doi.org/10.1037/0278-6133.26.2.152

Knowles, A. M., Niven, A., \& Fawkner, S. (2011). A Qualitative Examination of Factors Related to the Decrease in Physical Activity Behavior in Adolescent Girls During the Transition from Primary to Secondary School. Journal of Physical Activity and Health, 8(8), 1084-1091. https://doi.org/10.1123/jpah.8.8.1084

Knuth, A. G., \& Hallal, P. C. (2009). Temporal Trends In Physical Activity: A Systematic Review. Journal of Physical Activity and Health, 6(5), 548-559. https://doi. org/10.1123/jpah.6.5.548

Krane, V., Eklund, R., \& McDermott, M. (1991). Collaborative Action Research and Behavioral Coaching Intervention: A Case Study. Applied Research in Coaching and Athletics Annual, 6, 119-148.

Lonsdale, C., Hodge, K., \& Rose, E. A. (2008). The Behavioral Regulation in Sport Questionnaire (BRSQ): Instrument Development And Initial Validity Evidence. Journal of Sport and Exercise Psychology, 30, 323-355. https://doi.org/10.1123/jsep.30.3.323

Luiggi, M., Maïano, C., \& Griffet, J. (2019) Development and Initial Validation of Sport Experiences Questionnaire (SEQ), Journal of Leisure Research, 50:2, 132-156, https://doi.org/10.1080/00222216.2018.1554965

Luiggi M., Travert M., Griffet J. (2018) Temporal Trends in Sports Participation among Adolescents between 2001 and 2015: A French School- and Territory-Based Study. International Journal of Environmental Research and Public Health, 15(7):1335. https://doi.org/10.3390/ ijerph15071335

Malinauskas, R., \& Zablockis, ̌́. (2020). Features of the Sports Experience of Basketball Cadets and Juniors. In Pedagogical Advice: Experience, Research, Recommendations: Materials of the Intern. Scientificpractical Conf. (Cheboksary, January 27, 2020) (pp. 213-214). Cheboksary: "Interactive Plus".

Molanorouzi, K., Khoo, S., \& Morris, T. (2015). Motives for Adult Participation in Physical Activity: Type of Activity, Age, and Gender. BMC PublicHealth, 15, 66. https://doi.org/10.1186/s12889-015-1429-7

Nixon, H. L. (1992). A Social Network Analysis of Influence Athletes to Play with Pain and Injuries. Journal of Sport and Social Issues, 16(2), 127-135. https://doi. org/10.1177/019372359201600208

Nixon, H. L. (1993). Accepting the Risks of Pain and Injury in Sport: Mediated Cultural Influences on Playing 
Hurt. Sociology of Sport Journal, 10(2), 183-196. https:// doi.org/10.1123/ssj.10.2.183

Nixon, H. L. (1996). Explaining Pain and Injury Attitudes and Experiences in Sport in Terms of Gender, Race, and Sports Status Factors. Journal of Sport and Social Issues, 20(1), 33-44. https://doi. org/10.1177/019372396020001004

Owen, K. B., Smith, J., Lubans, D. R., Ng, J. Y. Y., \& Lonsdale, C. (2014). Self-determined Motivation and Physical Activity in Children and Adolescents: A Systematic Review and Meta-analysis. Preventive Medicine, 67, 270-279. https://doi.org/10.1016/j. ypmed.2014.07.033

Potrac, P., \& Cassidy, T. (2006). The Coach as a 'More Capable Other'. In The Sports Coach as Educator (pp. 57-68). London: Routledge.

Nelson L.J., Cushion C.J. \& Potrac P. (2006). Formal, Non Formal and Informal Coach Learning: a Holistic Conceptualization. International Journal of Sports Science \& Coaching, 1: 247-259

Pelletier, L. G., Rocchi, M. A., Vallerand, R. J., Deci, E. L., \& Ryan, R. M. (2013). Validation of the Revised Sport Motivation Scale (SMS-II). Psychology of Sport and Exercise, 14(3), 329-341. https://doi. org/10.1016/j.psychsport.2012.12.002

Phoenix, C., \& Orr, P. (2014). Pleasure: A Forgotten Dimension of Physical Activity in Older Age. Social Science and Medicine, 115, 94-102.

Ryan, R. M., \& Deci, E. L. (2007). Active Human Nature: Self-determination Theory and the Promotion and Maintenance of Sport, Exercise, and Health. In: M. S. Hagger, \&, N. L. D. Chatzisarantis. (Eds.), Intrinsic Motivation and Self-determination in Exercise and Sport (pp. 1-20). Champaign, IL: Human Kinetics

Saragiotto, B. T., di Pierro, C., \& Lopes, A. D. (2014). Risk Factors and Injury Prevention in Elite Athletes: A Descriptive Study of the Opinions of Physical Therapists, Doctors and Trainers. Brazilian Journal of Physical Therapy, 18(2), 137-143. https://doi.org/10.1590/ S1413-35552012005000147

Schnell, A., Mayer, J., Diehl, K., Zipfel, S., \& Thiel, A. (2014). Giving Everything for Athletic Success! Sportsspecific Risk Acceptance of Elite Adolescent Athletes. Psychology of Sport and Exercise, 15(2), 165-172. https://doi.org/10.1016/j.psychsport.2013.10.012

Solomon, G. B., Striegel, D. A., Eliot, J. F., Heon, S. N., Maas, J. L., \& Wayda, V. K. (1996). The Self-fulfilling Prophecy in College Basketball: Implications for Effective Coaching. Journal of Applied Sport Psychology, $8(1), 44-59$.

Moussa, O., da Silva, M. P., Ryan, C. A., \& Laflamme, R. (2012). Practical Experimental Certification of Computational Quantum Gates Using a Twirling
Procedure. Physical Review Letters, 109(7), 070504.

Smith, M., \& Cushion, C. J. (2006). An Investigation of the In-game Behaviours of Professional, Top-level Youth Soccer Coaches. Journal of Sports Sciences, 24(4), 355366.

Smith, J. \A. (1995) Semi Structured Interviewing and Qualitative Analysis. In: Smith, Jonathan A. and Harre, $R$. and Van Langenhove, L. (eds.) Rethinking Methods in Psychology (pp. 9-26). London: Sage Publications.

Solomon, G. B., Striegel, D. A., Eliot, J. F., Heon, S. N., Maas, J. L., \& Wayda, V.K. (2007). The Self-fulfilling Prophecy in College Basketball: Implications for Effective Coaching. Journal of Applied Sport Psychology, 8, 44-59.

Stalsberg, R., \& Pedersen, A. V. (2010). Effects of Socioeconomic Status on the Physical Activity in Adolescents: A Systematic Review of the Evidence. Scandinavian Journal of Medicine \& Science in Sports, 20(3), 368-383.

Suris, J. C., Michaud, P. A., Chossis, I., \& Jeannin, A. (2006). Towards a Sedentary Society: Trends in Adolescent Sport Practice in Switzerland (1993-2002). The Journal of Adolescent Health: Official Publication of the Society for Adolescent Medicine, 39(1), 132-134.

Texeira, P. J., Carraca, E. V., Markland, D., Silva, M. N., \& Ryan, R. M. (2012). Exercise, Physical Activity, and Self-determination Theory: A Systematic Review. International Journal of Behavioral Nutrition and Physical Activity, 9, 78. https://doi.org/10.1186/14795868-9-78

Uijtdewilligen, L., Nauta, J., Singh, A. S., van Mechelen, W., Twisk, J. W. R., van der Horst, K., \& Chinapaw, M. J. M. (2011). Determinants of Physical Activity and Sedentary Behaviour in Young People: A Review and Quality Synthesis of Prospective Studies. British Journal of Sports Medicine, 45(11), 896-905. https://doi.org/10.1136/bjsports-2011-090197

Van Cappellen, P., Rice, E. L., Catalino, L. I., \& Fredrickson, B. L. (2017). Positive Affective Processes Underlie Positive Health Behavior Change. Psychology \& Health, 12, 1-21.

Wang, X. (2011). The Role of Anticipated Negative Emotions and Past Behavior in Individuals' Physical Activity Intentions and Behaviors. Psychology of Sport and Exercise, 12(3), 300-305. https://doi.org/10.1016/j. psychsport.2010.09.007

Wirtz, D., Kruger, J., Scollon, C. N., \& Diener, E. (2003). What to do on Spring Break? The Role of Predicted, Online, and Remembered Experience in Future Choice. Psychological Science, 14(5), 520-524. https://doi. org/10.1111/1467-9280.03455

Yungblut, H. E., Schinke, R. J., \& McGannon, K. R. (2012). Views of Adolescent Female Youth on Physical Activity During Early Adolescence. Journal of Sports Science and Medicine, 11, 39-50. 